\title{
IRK-1 Potassium Channels Mediate Peptidergic Inhibition of Caenorhabditis elegans Serotonin Neurons via a $\mathrm{G}_{\mathrm{o}}$ Signaling Pathway
}

\author{
Lesley Emtage, ${ }^{1}$ Sonya Aziz-Zaman, ${ }^{1}$ Olivia Padovan-Merhar, ${ }^{2}$ H. Robert Horvitz,${ }^{3}$ Christopher Fang-Yen, ${ }^{2}$ \\ and Niels Ringstad ${ }^{1}$ \\ ${ }^{1}$ Skirball Institute of Biomolecular Medicine, Molecular Neurobiology Program, Department of Cell Biology, New York University Langone Medical Center, \\ New York, New York 10016, ${ }^{2}$ Department of Bioengineering, University of Pennsylvania, Philadelphia, Pennsylvania 19104, and ${ }^{3}$ Department of Biology \\ and Howard Hughes Medical Institute, Massachusetts Institute of Technology, Cambridge, Massachusetts 02139
}

To identify molecular mechanisms that function in G-protein signaling, we have performed molecular genetic studies of a simple behavior of the nematode Caenorhabditis elegans, egg laying, which is driven by a pair of serotonergic neurons, the hermaphroditespecific neurons (HSNs). The activity of the HSNs is regulated by the $\mathrm{G}_{\mathrm{o}}$-coupled receptor EGL-6, which mediates inhibition of the HSNs by neuropeptides. We report here that this inhibition requires one of three inwardly rectifying $\mathrm{K}^{+}$channels encoded by the $C$. elegans genome: IRK-1. Using ChannelRhodopsin-2-mediated stimulation of HSNs, we observed roles for egl-6 and irk-1 in regulating the excitability of HSNs. Although irk-1 is required for inhibition of HSNs by EGL-6 signaling, we found that other $\mathrm{G}_{\mathrm{o}}$ signaling pathways that inhibit HSNs involve irk-1 little or not at all. These findings suggest that the neuropeptide receptor EGL-6 regulates the potassium channel IRK-1 via a dedicated pool of $G_{0}$ not involved in other $G_{0}$-mediated signaling. We conclude that G-protein-coupled receptors that signal through the same G-protein in the same cell might activate distinct effectors and that specific coupling of a G-protein-coupled receptor to its effectors can be determined by factors other than its associated G-proteins.

\section{Introduction}

G-protein-coupled receptors (GPCRs) constitute a large family of cell surface receptors for diverse small molecules and peptides. In neurons, GPCRs act as receptors for most neurotransmitters and neuromodulators. Accordingly, GPCRs have critical functions in brain circuits, and they are targets of therapeutics used for the treatment of numerous psychiatric disorders, including schizophrenia, depression, anxiety disorders, and addiction (Iversen et al., 2009). GPCRs exert their effects on cell physiology by activating associated heterotrimeric G-proteins, which in turn regulate effectors such as protein kinases, ion channels, and enzymes that generate secondmessenger signals. Although G-protein signaling has been linked to many such effectors, how GPCR signaling alters cell and circuit function in vivo to change behavior is still poorly understood.

The egg-laying system of the nematode Caenorhabditis elegans is a powerful model for the study of G-protein signaling in the

Received June 4, 2012; revised Aug. 29, 2012; accepted Sept. 12, 2012.

Author contributions: L.E., S.A.-Z., O.P.-M., C.F.-Y., and N.R. designed research; L.E., S.A.-Z., O.P.-M., C.F.-Y., and N.R. performed research; H.R.H. contributed unpublished reagents/analytic tools; H.R.H., C.F.-Y., and N.R. analyzed data; L.E. and N.R. wrote the paper.

This work was supported by NIH Grant R01-GM024663 (H.R.H.) and NIH Grant R01-GM098320 (N.R.). N.R. is a Pew Scholar in the Biomedical Sciences. Some strains were provided by the Caenorhabditis Genetics Center, which is funded by the National Center for Research Resources. We thank Alexander Gottschalk for providing a ChR2 expression construct and Kara Zang for comments on this manuscript.

The authors declare no competing financial interests.

Correspondence should be addressed to Niels Ringstad at the above address. E-mail: niels.ringstad@ med.nyu.edu.

DOI:10.1523/JNEUROSCI.2667-12.2012

Copyright $\odot 2012$ the authors $\quad 0270-6474 / 12 / 3216285-11 \$ 15.00 / 0$ control of circuit function and behavior. Egg laying is driven by two motor neurons, the serotonergic hermaphrodite-specific neurons (HSNs), which innervate vulval muscles (White et al., 1986). Both the HSNs and vulval muscles are regulated by $\mathrm{G}$-protein signaling. Vulval muscles express two $\mathrm{G}_{\mathrm{q}}$-coupled serotonin receptors that promote muscle contraction: SER-1 and SER-7 (Carnell et al., 2005; Hobson et al., 2006). Egg-laying behavior is inhibited by $\mathrm{G}_{\mathrm{o}}$ signaling in the HSNs (Mendel et al., 1995; Ségalat et al., 1995; Tanis et al., 2008). HSNs express several receptors that inhibit egg laying in a $G_{o}$-dependent manner: the muscarinic acetylcholine receptor GAR-2 (Lee et al., 2000; Bany et al., 2003), the orphan receptor EGL-47 (Moresco and Koelle, 2004), and the neuropeptide receptor EGL-6 (Ringstad and Horvitz, 2008). These $\mathrm{G}_{\mathrm{o}}$-coupled receptors might coordinate egg laying with the activity of other neuronal circuits. For example, sources of RFamide neuropeptide ligands for EGL-6 include the BAG sensory neurons (Kim and Li, 2004; Ringstad and Horvitz, 2008), which are activated by hypoxia (Zimmer et al., 2009) and carbon dioxide (Hallem et al., 2011). $\mathrm{G}_{\mathrm{o}}$ signaling in the HSNs likely integrates inhibitory signals from multiple circuits outside of the reproductive neuromusculature, including sensory systems, to modulate egg-laying behavior.

Although $G_{o}$ signaling has long been known to mediate inhibition of the HSNs, the mechanism by which this inhibition occurs is unclear. At cholinergic neuromuscular synapses, $G_{0}$ signaling reduces levels of diacylglycerol, which potentiates synaptic vesicle fusion via the fusion regulator UNC-13 (Nurrish et al., 1999) and also promotes dense-core vesicle fusion by activat- 
ing protein kinase $C$ (Sieburth et al., 2007). In other contexts, $G_{o}$ can regulate neuronal function through other mechanisms. Vertebrate G-protein $\beta \gamma$ subunits once liberated from $\mathrm{G}_{\mathrm{o}} \alpha$ directly inhibits voltage-sensitive calcium channels (Herlitze et al., 1996) and activates potassium channels (Reuveny et al., 1994), reducing both neuronal excitability and presynaptic function. To better understand how $G_{o}$ signaling modulates neuronal function in vivo, we sought to identify genes required for inhibition of HSNs by the $\mathrm{G}_{\mathrm{o}}$-coupled neuropeptide receptor EGL-6. We report here a role for nematode Kcnj family potassium channels in the modulation of HSNs by inhibitory $\mathrm{G}_{\mathrm{o}}$ signaling.

\section{Materials and Methods}

Strains. C. elegans hermaphrodites were grown on nematode growth medium (NGM) agar at $20^{\circ} \mathrm{C}$ on Escherichia coli OP50 as described previously (Brenner, 1974). Wild-type C. elegans were the Bristol N2 strain. Other strains used in this study were as follows: MT15934 irk-1(n4895), FQ295 irk-2(n4896), MT17360 irk-3(n5049), MT1222 egl-6(n592), MT16668 egl6(n592) irk-1(n4895), MT16693 egl-6(n592) irk-2(4896), FQ308 egl-

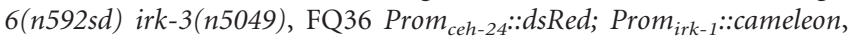

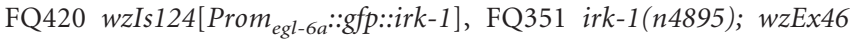
[Prom $_{\text {egl-6a: }}:$ irk-1 Prom $_{\text {ttx- }-3}::$ dsRed], FQ352 irk-1(n4895); wzEx47 [Prom $_{\text {egl-6a }}:$ irk-1 Prom $_{\text {ttx-3 }}::$ dsRed], FQ353 irk-1(n4895); wzEx48 Prom $_{\text {egl-6a }}::$ irk-1 Prom $_{\text {ttx }-3}::$ dsRed], FQ370 egl-6(n592); wzEx52 Prom $_{\text {egl-6a: }}:$ irk-1RNAi sense Prom egl-6a $_{1}:$ irk-1RNAi antisense

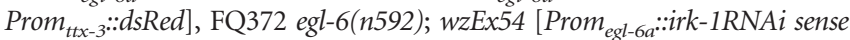
Prom $_{\text {egl-6a: }: i r k-1 R N A i}$ antisense Prom $\left.{ }_{\text {ttx- }-3}:: d s R e d\right]$, FQ373 egl-6(n592sd); wzEx55[Prom egl-6a $:: i r k-1 R N A i$ sense Prom $_{\text {egl-6a }}:$ irk-1RNAi antisense

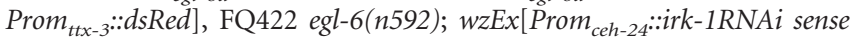
Prom $_{\text {ceh-24 }}::$ irk-1RNAi antisense Prom $_{t t x-3}:: d_{s}$ Red], FQ342 wzEx41 [Prom $_{\text {egl-6a }}:$ irk-1 Prom $_{\text {ttx-3 }}::$ dsRed], FQ343 egl-6(n4536); wzEx41

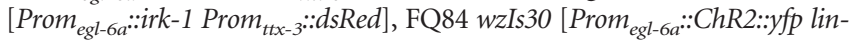

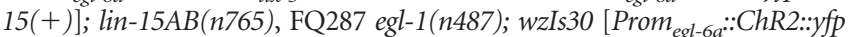
lin-15(+)]; lin-15AB(n765), FQ200 irk-1(n4895); wzIs30 [Prom $_{\text {egl-6a }}:$ ChR2:::yfp lin-15(+)]; lin-15AB(n765), FQ201 irk-3(n5049) irk-

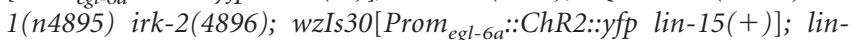

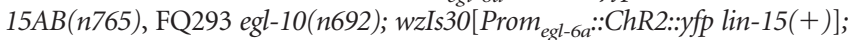

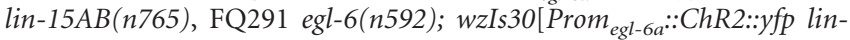
15(+) ]; $\operatorname{lin}-15 A B(n 765), \mathrm{FQ310}$ egl-6(n592) irk-1(n4895); wzIs30

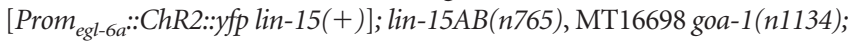
egl-6(n592), FQ309 goa-1(n1134); egl-6(n592) irk-1(n4895), FQ281 egl10(n692);) irk-1(n4895), FQ280 egl-47(n1081); irk-1(n4895).

irk-1, irk-2, and irk-3 deletion alleles and egl-6(n592), egl-10(n692), egl-47(n1081), and goa-1(n1134) mutations were followed and verified using PCR; primers that specifically amplified sequences containing point mutations were designed as previously described (Drenkard et al., 2000).

Transgenic animals were created according to Mello et al. (1991). The Prom $_{\text {ttx-3 }}::$ dsRed coinjection marker was used at $40 \mathrm{ng} \mu \mathrm{l}^{-1}$. A lin-15 rescuing plasmid pL15EK was used at $30 \mathrm{ng}_{\mu \mathrm{l}^{-1}}$. Prom $_{\text {irk-1 }}::$ cameleon

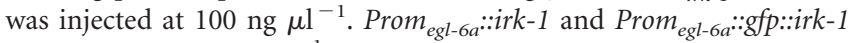

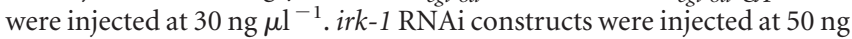

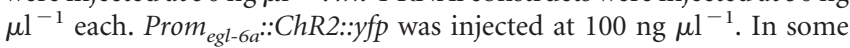
cases, extrachromosomal transgenes were integrated using gamma radiation (5000 rad).

Isolation of deletion alleles. Libraries of mutagenized animals were constructed and screened by PCR for deletion alleles of irk-1, irk-2, and irk-3, essentially as described previously (Jansen et al., 1997). Deletion mutants were isolated from frozen stocks and backcrossed to wild-type worms at least four times.

Molecular biology. PCR-amplified promoter sequences and cDNAs were initially cloned into the pGEM-T Easy vector (Promega) and sequenced. Promoter sequences, cDNA sequences, and coding sequences used for expression of dsRNA targeting irk-1 were subcloned into the modular C. elegans expression vector pPD49.26 (Mello and Fire, 1995) using standard methods. cRNA for expression in Xenopus oocytes was generated from cDNAs clones into the vector pGEMHE (Liman et al., 1992). irk-1 cDNA was amplified by PCR from cDNA created using the SuperScript III First-Strand
Table 1. Exact $p$ values calculated from pairwise comparisons of measurements of egg-laying behavior by the indicated strains

\begin{tabular}{|c|c|c|}
\hline Genotype 1 & Genotype 2 & $p$ \\
\hline$e g l-6(g f)$ & egl-6(gf) irk-1( $(\Delta)$ & $1.3 \mathrm{E}-15$ \\
\hline$e g l-6(g f)$ & $\operatorname{irk}-2(\Delta)$ egl-6(gf) & $1.7 \mathrm{E}-5$ \\
\hline$e g l-6(g f)$ & egl-6(gf) irk-3( $\Delta)$ & $1.3 \mathrm{E}-15$ \\
\hline Wild type & $\operatorname{irk}-1(\Delta)$ & $3.9 \mathrm{E}-11$ \\
\hline Wild type & $\operatorname{irk}-2(\Delta)$ & $1.0 \mathrm{E}-1$ \\
\hline Wild type & $\operatorname{irk}-3(\Delta)$ & $3.0 \mathrm{E}-3$ \\
\hline egl-6(gf) & egl-6(gf); irk-1 RNAi in HSNs & $6.6 \mathrm{E}-16$ \\
\hline$e g l-6(g f)$ & egl-6(gf); irk-1 RNAi in vulval muscles & $5.2 \mathrm{E}-1$ \\
\hline Wild type & irk-1 overexpression in HSNs & $6.6 \mathrm{E}-16$ \\
\hline$e g l-6(\Delta)$ & irk-1 overexpression in HSNs & $7.6 \mathrm{E}-1$ \\
\hline goa-1(If); egl-6(gf) & goa-1(lff); egl-6(gf) irk-1(B) & $1.7 \mathrm{E}-1$ \\
\hline goa-1 & 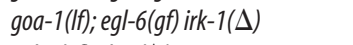 & $2.8 \mathrm{E}-7$ \\
\hline egl-6(gf) & egl-6(gf) irk-1 $(\Delta)$ & $2.2 \mathrm{E}-16$ \\
\hline egl-10(If) & egl-10(If); irk-1( $(\Delta)$ & $1.5 \mathrm{E}-6$ \\
\hline$e g l-47(g f)$ & egl-47(gf); irk-1( $\Delta)$ & $4.2 \mathrm{E}-3$ \\
\hline
\end{tabular}

Values of $p$ from egg stage data were calculated using the nonparametric Wilcoxon Mann-Whitney rank sum test and corrected for multiple comparisons using a Bonferroni correction.

Synthesis kit (Invitrogen). Primers used to amplify irk-1 cDNA were as follows: 5'-ATGACGCTTTCAGTCCCGGATTGC-3' and 5'-CTACGTCTCG CTGACGATTTCAATG-3' . Primers used to amplify a $6.5 \mathrm{~kb}$ irk-1 promoter were as follows: $5^{\prime}$-CAACATAAACTTTGGTTTCGAATGTGG-3' and $5^{\prime}$ CATTGATCTGAAAAATGTATG-3'. Primers used to amplify a $3.5 \mathrm{~kb}$ egl-6a promoter were as follows: $5^{\prime}$-GCAAAAATCTAGAGGTCTG-3' and 5'-TGTGTTCTATGATGTTCTCCATC-3'.

Microscopy. Young adults were anesthetized with $30 \mathrm{~mm}$ sodium azide and mounted on $2 \%$ agarose pads made in M9 medium. $Z$ stacks were obtained with a Zeiss LSM510 confocal microscope, and maximumprojection images were created using ImageJ (W. S. Rasband, ImageJ, National Institutes of Health, Bethesda, MD; http://imagej.nih.gov/ij/; 1997-2011). HSNs were identified on the basis of cell body position and neurite morphology. Other irk-1-expressing cells were identified as neurons on the basis of their nuclear morphology observed using differential interference contrast (DIC) optics.

Xenopus oocyte electrophysiology. Capped irk-1 cRNAs were prepared using the mMessage Machine kit (Ambion). X. laevis oocytes were injected with $50 \mathrm{ng} \mu \mathrm{l}^{-1}$ irk-1 sense cRNA. Injected oocytes were incubated at room temperature in ND96 medium $(96 \mathrm{~mm} \mathrm{NaCl}, 2.5 \mathrm{~mm} \mathrm{KCl}, 1 \mathrm{~mm}$ $\mathrm{MgCl}_{2}$, and $5 \mathrm{~mm}$ HEPES, $\mathrm{pH}$ 7.6) for 2-5 d before recording. Whole-cell current recordings were made using a two-electrode voltage-clamp (Warner Instruments). Oocytes were continuously superfused with ND96 during measurements of the resting membrane potential. To assay activity of IRK channels, we equilibrated oocytes in high- $\mathrm{K}^{+}$medium ( $96 \mathrm{~mm} \mathrm{KCl}$ and $2.5 \mathrm{~mm} \mathrm{NaCl}$ instead of $2.5 \mathrm{~mm} \mathrm{KCl}$ and $96 \mathrm{~mm} \mathrm{NaCl}$ ) to permit measurement of inward currents. Data were acquired with a Digidata 1440 digitizer (Molecular Devices) and analyzed off-line with Clampfit (Molecular Devices). All experiments using Xenopus laevis were performed according to guidelines of the Committee on Animal Care at New York University Medical Center.

Behavioral assays. All behavioral assays were performed on C. elegans hermaphrodites. For assays of egg-laying behavior, five young nongravid hermaphrodites were transferred to a fresh plate seeded with OP50 bacteria and allowed to lay eggs for $1 \mathrm{~h}$. These experiments were performed with at least 20 animals. Newly laid eggs were transferred to a $2 \%$ agarose pad in M9 buffer and observed at $100 \times$ (late stage) or $1000 \times$ (early stage) magnification using a Zeiss Axioskop equipped with Nomarski/ DIC optics and scored as being in one of seven categories: $1-8$ cell embryos, 9-25 cell embryos, embryos with $>26$ cells that had not undergone overt morphogenesis, comma stage embryos, twofold embryos, threefold embryos, and embryos that hatched during the observation period and appeared as L1 larvae.

To measure locomotory behavior of C. elegans strains, 30 young adult hermaphrodites were transferred to a fresh NGM agar plate coated with a thin lawn of E. coli OP50 and allowed to recover for $1 \mathrm{~h}$. Animals were visualized with a custom-built LED ring light. Video was captured at 7.5 


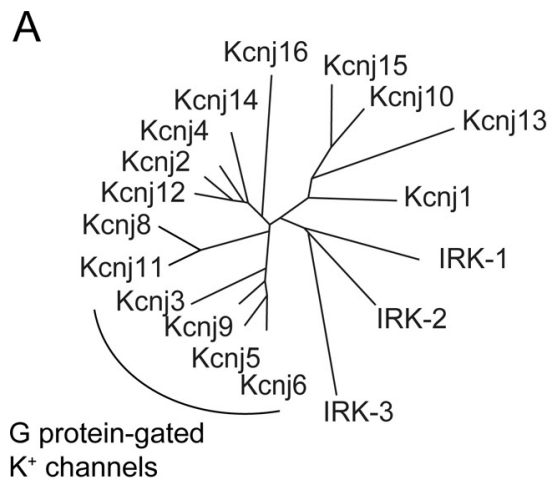

B
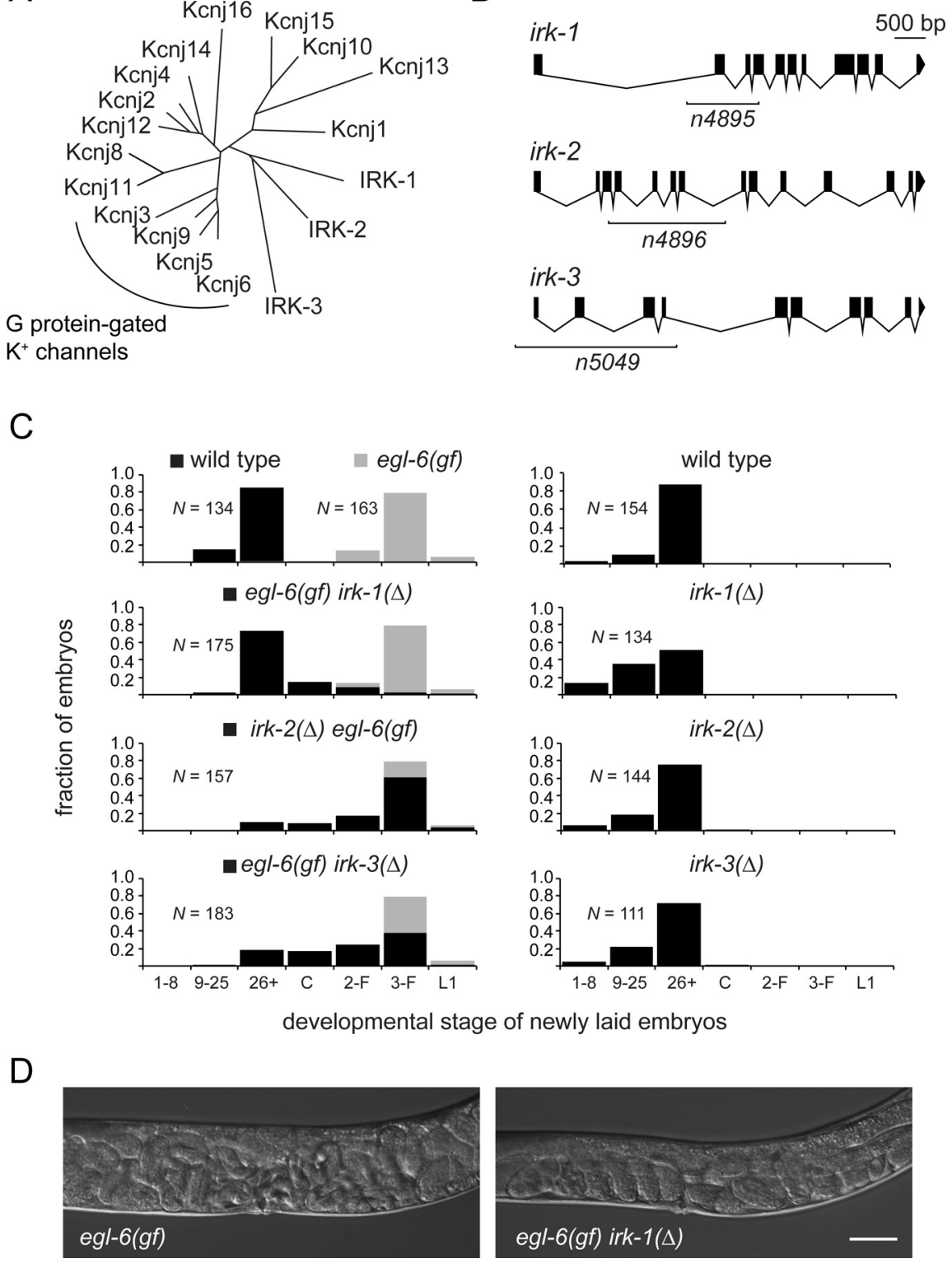

ewly laid embryos

Figure 1. A C. elegans gene predicted to encode an inward-rectifier potassium channel subunit is required for inhibitory neuropeptide signaling. $A$, The $C$. elegans genome is predicted to encode three members of the Kcnj family of two-pore inward rectifier potassium channels: IRK-1, IRK-2, and IRK-3. A molecular phylogeny of C. elegans and mammalian Kcnj-like channel subunits was computed based on ClustalW sequence alignment. $\boldsymbol{B}$, Intron- exon organization of the three $\boldsymbol{C}$. elegans irk genes. Sequences missing in deletion alleles are indicated by brackets. $\boldsymbol{C}$, irk-1 is required for inhibition of egg-laying behavior by the neuropeptide receptor EGL-6. A gain-of-function mutation in egl-6 decreases the frequency of egg laying and shifts the developmental stage of newly laid embryos, which were scored as 1-8 cell embryos, $9-25$ cell embryos, embryos with 26 or more cells, comma stage embryos (C), twofold embryos (2-F), threefold embryos (3-F), or embryos that hatched during the observations period (L1). egl-6(gf) data are plotted in light gray. Deletion of irk-1 but not of irk-2 or irk-3 suppressed this behavioral phenotype (left column). In an otherwise wild-type background, irk gene deletions caused either no effect or only a slight shift toward earlier developmental stages, reflecting an increase in the frequency of egg laying (right column). $\boldsymbol{D}$, irk-1 deletion suppresses the bloating of egl-6(gf) mutants with unlaid eggs. Scale bar, $50 \mu \mathrm{m}$.

frames per second using a Unibrain Fire-i785 camera and the MATLAB Image Acquisition Toolbox (MathWorks). Individual worm trajectories were computed using the Mosaic plugin for ImageJ (Sbalzarini and Koumoutsakos, 2005). Centroid speeds of worms that were tracked for at least 140 consecutive frames were calculated using MATLAB (MathWorks).

For structured illumination of immobilized animals expressing ChannelRhodopsin-2 (ChR2), animals were placed on pads composed of $2 \%$ agarose in NGM buffer and immobilized using $0.1-\mu \mathrm{m}$-diameter polystyrene beads as described previously (Fang-Yen et al., 2012). To create structured illumination, we used a $473 \mathrm{~nm}$ laser coupled through a Leica inverted microscope via a digital micromirror device (Texas Instruments) in an optical setup similar to one previously described (Leifer et al., 2011). Worms were illuminated at an irradiance of $3 \mathrm{~mW} / \mathrm{mm}^{2}$ in one of two spatiotemporal patterns: (1) illumination of a $60 \mu \mathrm{m}$-square region centered around the vulva for $10 \mathrm{~s}$ followed by illumination of the entire field of view for $10 \mathrm{~s}$, or (2) illumination of the entire field of view except for the 60 $\mu \mathrm{m}$-square region around the vulva for $10 \mathrm{~s}$, followed by $10 \mathrm{~s}$ illumination of the entire field of view. A worm was scored as responsive if it laid one or more eggs during the first period of illumination.

For photostimulation of unrestrained animals, animals expressing ChR2 were placed on OP50 plates either with or without all-transretinal (ATR), prepared as previously described (Guo et al., 2009). Animals were transferred from these plates to conventional OP50 plates the next day and immediately assayed for egg laying in response to blue light. Assays were conducted using a Leica M165FC fluorescence stereo microscope equipped with a GFP filter set. Fluorescence illumination was provided by a Leica EL6000 light source with an internal shutter controlled by a programmable timer (Koyo KT-V). Irradiance was altered using filters and by varying the diameter of the light beam using the zoom optics of the microscope. Irradiance was calculated using power measurements and beam diameter at the surface of the cultivation plate.

Statistical methods. Values of $p$ from pairwise comparisons of egg stage data from different strains were calculated using the Wilcoxon Mann-Whitney rank sum test as implemented in the Coin package of the R statistical analysis program (R Development Core Team, R Foundation for Statistical Computing, Vienna, Austria; http://www.R-project.org). These $p$ values are presented in Table 1. Other statistical analyses were performed using GraphPad Prism software.

\section{Results}

One of three inward rectifier potassium channels encoded by the $C$. elegans genome is required for inhibition mediated by the neuropeptide receptor EGL-6

$n 592$ is a gain-of-function (gf) mutation that increases function of the neuropeptide receptor EGL-6, which inhibits the HSN neurons of the egg-laying system. Importantly, the $n 592$ mutant receptor is still regulated by endogenous RFamide peptide ligands and requires $\mathrm{G}_{\mathrm{o}}$-proteins (Ringstad and Horvitz, 2008). We sought to identify genes that function in $G_{o}$ signaling by identifying genetic suppressors of the egg-laying defects of egl-6(gf) mutants. In the mammalian nervous system, inhibitory GPCRs regulate potassium channels of the Kcnj family, which are inwardly rectified tetrameric potassium channels comprising subunits with two 
transmembrane domains flanking a poreforming loop (Luján et al., 2009). The $C$. elegans genome is predicted to encode three such channel subunits (Bargmann, 1998): IRK-1, IRK-2, and IRK-3 (Fig. 1A). To determine whether any of these channels is required for inhibitory EGL-6 signaling, we isolated deletion alleles of each irk gene (Fig. $1 \mathrm{~B}$ ) and tested whether loss of IRK channels suppressed the egg-laying defect caused by egl-6(gf).

We measured the egg-laying behavior of the wild-type, egl-6(gf), and egl-6(gf) irk double mutants by scoring the developmental stage of newly laid eggs, which reflects the time embryos spent in utero before being released. As expected (Ringstad and Horvitz, 2008), embryos laid by egl-6(gf) mutants were abnormally late stage, having developed to the threefold stage and in some cases having already hatched by the time of observation (Fig. $1 C)$. Deletion of irk-2 did not suppress the egl-6(gf) phenotype, and deletion of irk-3 only slightly modified the egl-6(gf) phenotype (Fig. 1C). irk-1 deletion, however, strongly suppressed the egl-6(gf) phenotype: egl-6(gf) irk-1 $(\Delta)$ mutants laid most embryos at a normal developmental stage (Fig. 1C), and egl-6(gf) irk-1( $\Delta$ ) mutants were not bloated with unlaid eggs as young adults (Fig. 1D).

In contrast to its strong action as a suppressor of the egl-6(gf) phenotype, we found that the irk-1 deletion in a wildtype background conferred only a very mild defect in egg-laying behavior (Fig. $1 C$ ), suggesting that the constitutive role IRK-1 plays in regulating egg laying under normal culture conditions is minor. These results are consistent with the observation that vertebrate Kcnj channels expressed by neurons demonstrate low constitutive activity in the absence of activation of neurotransmitter signaling pathways (Takigawa and Alzheimer, 2002). Neither irk-2( $\Delta)$ nor irk-3( $\Delta)$ animals had overt defects in egg-laying behavior (Fig. 1C). These data suggest that, of the three Kcnjlike subunits encoded by the C. elegans genome, IRK-1 plays a role in modulating the function of the egg-laying system of the adult hermaphrodite, while IRK-2 and IRK-3 subunits either have minor roles in the egg-laying system or function in other tissues that weakly modulate the egg-laying system.

\section{IRK-1 channels are required in HSN neurons for inhibition} by EGL-6 signaling

Where does irk-1 function to regulate egg laying by C. elegans? We determined the cellular expression pattern of irk-1 using a reporter transgene that drives $y f p$ expression with the irk-1 promoter. We observed reporter transgene expression in neurons in

C

D

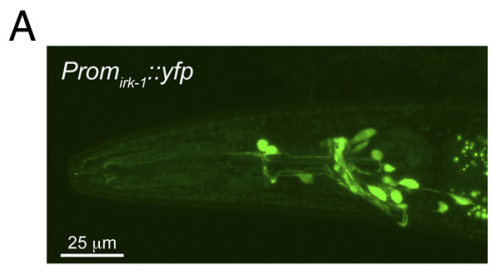

B
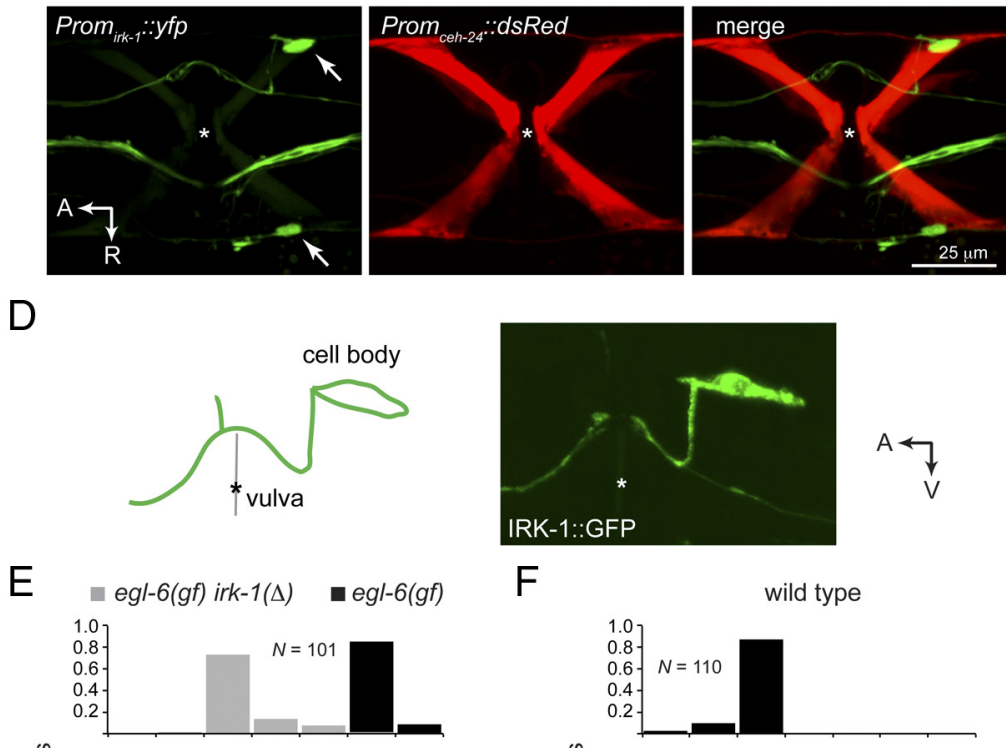

$\mathrm{F}$
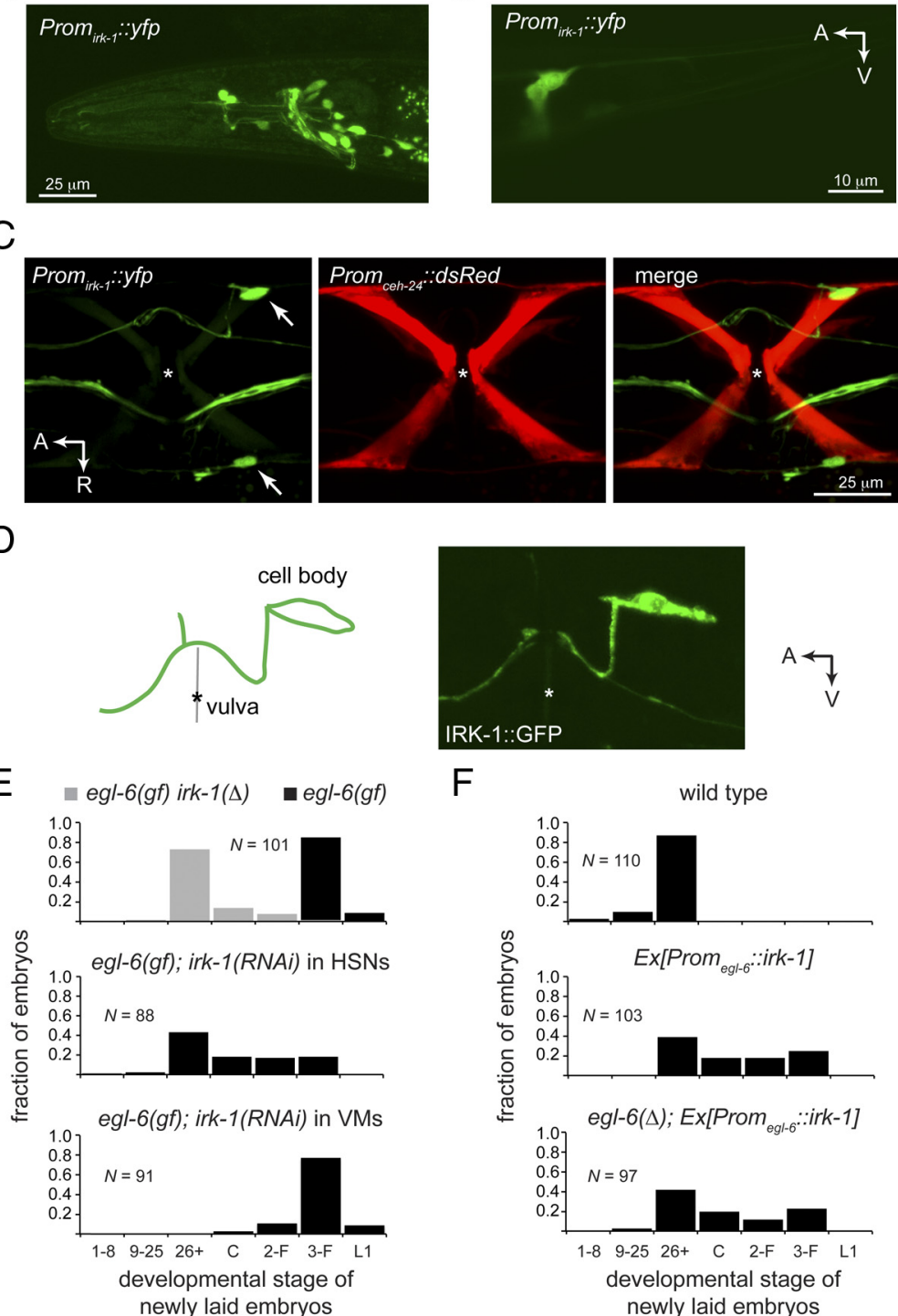

Figure 2. IRK-1 channels function in the serotonergic HSN neurons of the C. elegans egg-laying system. $\boldsymbol{A}$, Expression of a transcriptional irk-1 reporter transgene in the head of an adult hermaphrodite (lateral view). Approximately 20 neurons expressed this reporter. No expression of this reporter in non-neuronal cells was observed. $\boldsymbol{B}$, Expression of a transcriptional irk-1 reporter transgene in the tail of an adult hermaphrodite (lateral view). Two neurons express this reporter; no expression in non-neuronal cells was observed. A, Anterior; V, ventral. C, Expression of a transcriptional irk-1 reporter transgene in the egg-laying system of an adult hermaphrodite (ventral view). The HSN motor neurons, indicated by arrows, strongly express the irk-1 reporter. Faint expression in vulval muscles, expressing the red fluorophore dsRed, was observed. A, Anterior; $R$, right. The position of the vulval opening is indicated by an asterisk. $D$, A translational fusion of GFP to the $N$ terminus of IRK- 1 is expressed on both the HSN cell body and neurite, which is presynaptic to vulval muscles. $\boldsymbol{E}$, irk-1(RNAi) in HSNs but not vulval muscles suppresses the egg-laying defects of egl-6(gf) mutants. Egg-laying behavior of strains with the indicated genotypes was analyzed by measuring the developmental stage of newly laid eggs. egl-6(gf) irk-1( $\Delta)$ data from Figure 1 are replotted in light gray. The egl-6 promoter was used to drive expression of dsRNA targeting irk-1 transcripts in HSNs, and the ceh-24 promoter was used to express irk-1 dsRNA in vulval muscles. $\boldsymbol{F}$, IRK-1 channels inhibit HSNS downstream of or in parallel to the neuropeptide receptor EGL-6. The egg-laying behavior of wild-type or egl-6 mutant animals expressing irk- 1 in the HSNs was determined by measuring the developmental stage of newly laid eggs. The egl-6 promoter was used to specifically express irk-1 in HSNs.

the head and tail (Fig. 2A,B); we also observed expression of irk-1 in the egg-laying system (Fig. 2C). We observed strong expression of Prom $_{\text {irk- } 1}: \because y f p$ in the HSN motor neurons of the egg-laying system (Fig. 2C), and faint expression of this reporter in vulval muscles, which are postsynaptic to the HSNs.

To determine the subcellular localization of IRK-1 in the HSNs, we fused GFP to the IRK-1 N terminus and used the egl-6a promoter to drive expression of the fusion protein in HSNs. The 
A

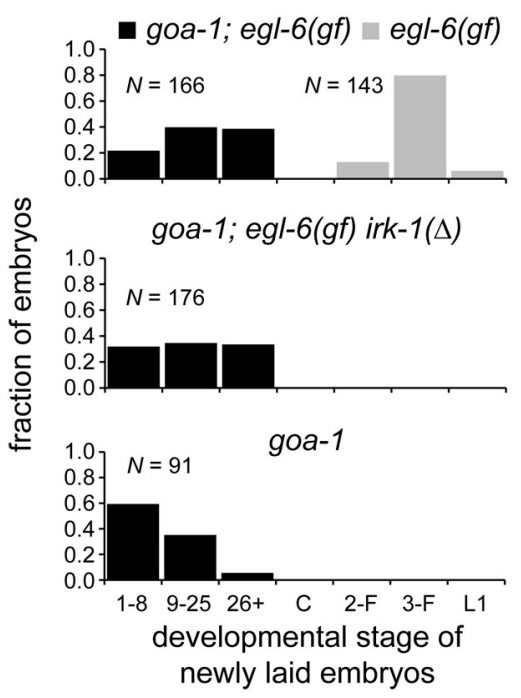

B

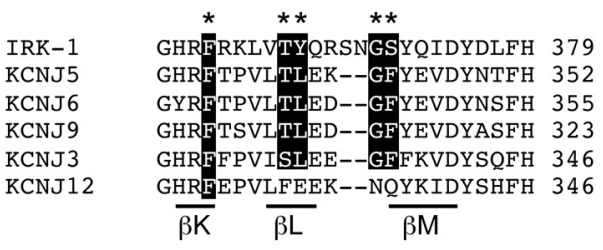

C

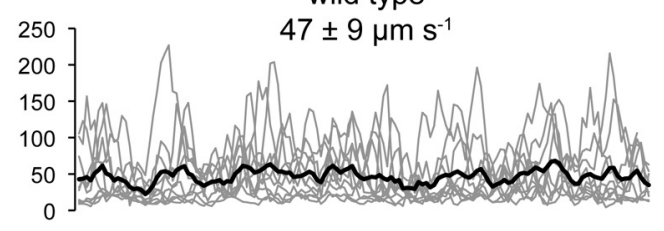

goa-1

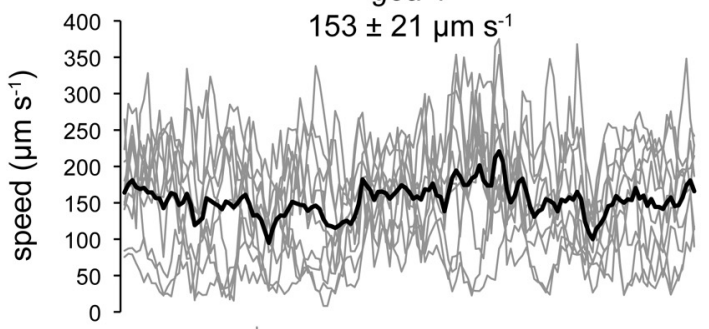

irk-1

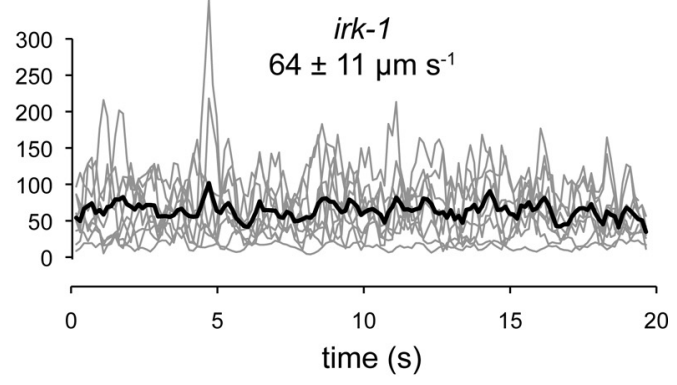

Figure 3. Deletion of irk-1 does not enhance the suppression of EGL-6 signaling by goa-1 mutation. $A$, The egg-laying behavior of egl-6(gf) mutants, goa-1; egl-6(gf) double mutants, goa-1; irk-1 $(\Delta)$ egl-6(gf) triple mutants, and goa-1 mutants was analyzed by measuring the developmental stage of newly laid eggs. $\boldsymbol{B}$, Residues implicated in regulation of Kcnj channels by $\mathrm{G}$-proteins are conserved between IRK-1 and vertebrate channel subunits. The vertebrate $\mathrm{K} \mathrm{cnj3}$, Kcnj5, Kcnj6, and Kcnj9 subunits are constituents of G-protein-gated potassium channels, while Kcnj12 is a constituent of channels that are not directly gated by G-proteins. Three $\beta$ strands, $\beta \mathrm{K}, \beta \mathrm{L}$, and $\beta \mathrm{M}$, contain residues that have been implicated in regulation of $\mathrm{K} \mathrm{cnj}$
HSNs are monopolar neurons and form synapses with target muscles and other neurons in the egg-laying system at stereotyped positions along the neurite (Fig. 2D). We observed GFP::IRK-1 on both the HSN soma and neurite (Fig. 2D). GFP::IRK-1 was not appreciably enriched at HSN presynaptic specializations. An EGL-6::GFP translational reporter is similarly expressed on the HSN soma and neurite without being markedly enriched in specific membrane domains (e.g., synapses) (Ringstad and Horvitz, 2008). These data suggest that IRK-1 channels are uniformly expressed on the HSN plasma membrane and not restricted to a specific region of the cell. It is possible, however, that the reporter transgenes used for these experiments are not localized to subcellular compartments either because the GFP tag interferes with such localization or because they are expressed at levels that saturate mechanisms required for their localization.

To determine whether irk-1 is required for EGL-6 signaling in the HSNs, where EGL-6 is expressed, or whether loss of irk-1 function in vulval muscles bypasses the inhibition of HSNs caused by EGL-6(gf), we created transgenes that express doublestranded irk-1 RNAs in a cell type-specific manner. Expression of irk-1 dsRNA in the HSN neurons potently suppressed the egglaying defects of egl-6(gf) mutants, recapitulating the phenotype of irk-1 mutants (Fig. 2E). By contrast, expression of the same irk-1 dsRNA using a promoter that drives expression in vulval muscles did not suppress the egl-6(gf) phenotype. Together, these data indicate that loss of irk-1 function in the HSN neurons alleviates the inhibition caused by increased EGL-6 signaling.

We next tested whether increased activity of irk-1 in HSNs mimics the effect of increased EGL-6 signaling (i.e., inhibits egglaying behavior). Animals carrying a transgene that drives irk-1 expression using the HSN-specific promoter of egl-6a were markedly defective in egg-laying behavior (Fig. $2 F$ ). This effect of increased irk-1 gene dosage was not suppressed by deleting the egl-6 gene, suggesting that IRK-1 channels function downstream of or in parallel to the EGL-6 GPCR (Fig. 2 F).

\section{The effects of loss of IRK-1 channels and loss of GOA-1/G $\alpha$ on egg-laying behavior are not additive}

Although EGL-6 requires IRK-1 to inhibit HSN neurons, it is possible that this dependency does not involve $G_{o}$ signaling, since some GPCRs can activate signaling pathways in a G-proteinindependent manner (Lefkowitz and Shenoy, 2005; Lu et al., 2009). We used a genetic interaction test to determine the functional relationship between IRK- 1 channels and $\mathrm{G}_{\mathrm{o}} \alpha$. If IRK-1 were required for inhibition of the HSN by the EGL-6 GPCR independently of G-proteins, then irk-1 $(\Delta)$ would modify the egl-6(gf) phenotype even in the absence of $\mathrm{G}_{\mathrm{o}} \alpha$. We used a severe loss-of-function allele of goa-1 to make a triply mutant strain defective in both irk-1 and goa-1 in an egl-6(gf) background, and we compared its egg-laying phenotype with that of egl-6(gf) animals that carried either a goa-1(lf) mutation or an irk-1( $\Delta)$ mutation (Fig. 3A). We found that deleting irk-1 did not significantly affect the egg-laying behavior of $g o a-1(l f)$; egl-6(gf) mutants (Fig.

channels by G-protein subunits (Whorton and MacKinnon, 2011) and are marked with asterisks These residues are conserved between IRK-1 and subunits of G-protein-gated channels but not between $\mathrm{G}$-protein-gated $\mathrm{K} c \mathrm{nj}$ channels and $\mathrm{Kcnj} 12$. C, irk- 1 is not required for $\mathrm{G}_{0}$ inhibition of locomotory behavior. Instantaneous speeds of wild-type, irk-1, and goa- 1 hermaphrodites on a bacterial lawn were recorded for $20 \mathrm{~s}$. The light gray traces represent the speed of individual worms during the session. The black traces represent the average instantaneous speed of the recorded individuals; the average speed \pm SD was computed from all speed measurements of animals of a given strain. $N=10$ animals per genotype. 
A
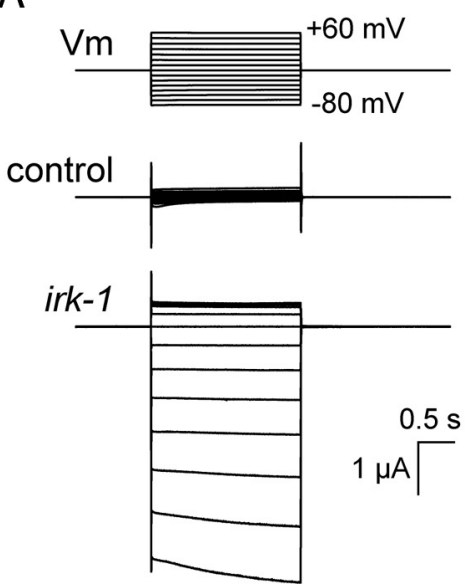

B

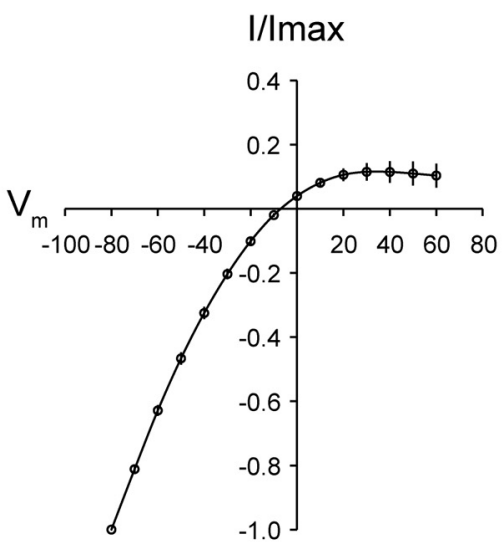

C

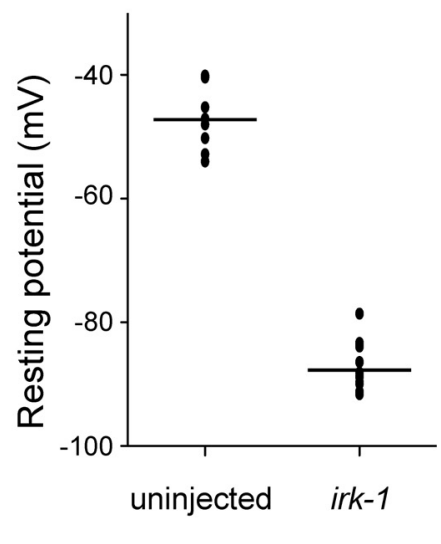

Figure 4. IRK-1 forms homomeric inward-rectifier potassium channels in vitro. A, Xenopus oocytes injected either with irk-1 cRNA or water were superfused with high-potassium saline, voltage clamped at $-10 \mathrm{mV}$, and subjected to a series of voltage steps from -80 to $+60 \mathrm{mV}$ as shown in the top trace. Water-injected control oocytes showed small nonrectified whole-cell currents, while irk-1-expressing 0ocytes showed large inwardly rectified whole-cell currents. $\boldsymbol{B}$, The current-voltage relationship of oocytes expressing irk-1. Whole-cell currents were measured at holding potentials between -80 and $+60 \mathrm{mV}$, normalized to the peak inward current measured at $-80 \mathrm{mV}$, and plotted. Shown are mean whole-cell currents normalized to the maximum inward current measured at $-80 \mathrm{mV}(N=8) \pm$ SEM. C, irk-1 expression shifts the resting potential of Xenopus oocytes toward the reversal potential for potassium. The resting potential of uninjected oocytes and oocytes injected with $50 \mathrm{ng}$ of irk-1 CRNA was measured in standard saline. The resting potentials of individual control and irk-1-expressing 00 cytes are plotted as circles; the mean resting potentials are plotted as horizontal lines.

$3 A)$. The failure of irk-1 deletion to enhance the suppression of egl-6(gf) by goa-1(lf) could not be attributed to a saturating effect of $g o a-1(l f)$ on the egg-laying system; goa-1(lf) mutants laid earlier stage eggs than did suppressed egl-6(gf) mutants (Fig. $3 A$ ). These data indicate that IRK-1 acts downstream of or in parallel to $G_{o} \alpha$ and suggest that the function of IRK-1 is regulated by $\mathrm{G}$-protein signaling. Indeed, sequences required for regulation by G-proteins of mammalian inward-rectifier potassium channels are conserved between those channels and IRK-1 (Fig. 3B), suggesting that IRK-1 channels might be directly targeted by G-proteins.

The failure of irk-1 to enhance suppression of the Egl-6(gf) phenotype by goa- 1 suggests that irk-1 and goa- 1 function in a common pathway. We tested whether irk-1 mutants have other behavioral defects in common with goa-1 mutants. In addition to hyperactive egg-laying behavior, goa-1 mutants also display hyperactive locomotory behavior (Mendel et al., 1995; Ségalat et al., 1995). We compared the locomotory behavior of irk-1 mutants with that of goa-1 mutants and found that irk-1 mutants did not display the hyperactivity characteristic of goa-1 mutants (Fig. $3 C$ ). The role of irk-1 in $\mathrm{G}_{\mathrm{o}}$ signaling, therefore, seems to be specific to the egg-laying system of C. elegans.

\section{IRK-1 forms homomeric inwardly rectified $\mathrm{K}^{+}$channels}

We identified C. elegans IRK channels as candidate effectors of EGL-6 signaling by their sequence homology to mammalian Kcnj channels. Nematode IRK channels, however, have not been functionally characterized. To determine the functional properties of IRK-1, we reconstituted IRK-1 channels in Xenopus oocytes. IRK-1 expression conferred upon oocytes a large inwardly rectified current (Fig. $4 A, B$ ) that reversed near the reversal potential for potassium, which in our experiment was close to $0 \mathrm{mV}$. Although IRK-1 currents were rectified, we nonetheless observed significant outward currents in IRK-1-expressing oocytes (Fig. $4 A, B)$, and IRK-1 expression caused the resting membrane potential of oocytes to be close to the reversal potential of potassium (Fig. 4C). In vitro, therefore, IRK-1 subunits are sufficient to form homomeric potassium channels that are strongly, but not com- pletely, inwardly rectified. IRK-1 channels have detectable constitutive activity when overexpressed in Xenopus oocytes, as do other members of the Kcnj channel family (Kubo et al., 1993).

\section{$\mathrm{G}_{\mathrm{o}}$ signaling and IRK-1 channels regulate the excitability of the HSN neurons}

In vertebrates, inward rectifier potassium channels regulate the excitability of neurons (Lüscher et al., 1997). Because of the strong genetic interaction between irk-1 and egl-6, we hypothesized that EGL-6 signaling inhibits the excitability of HSN neurons in a manner that depends on IRK-1 channels. To test this hypothesis, we generated transgenic animals that express ChR2 (Nagel et al., 2005) using the egl-6 promoter. This transgene allowed us to deliver defined excitatory stimuli to the HSNs. The egl-6 promoter drives transgene expression in a small number of cells including the HSNs (Ringstad and Horvitz, 2008). To ensure that behavioral responses to photostimulation could be attributed to activation of the HSN neurons, we used structured illumination to functionally map the site of ChR2 action in Prom $_{\text {egl-6.: }}$ ChR2-expressing animals. Blue light illumination of the midbody, where the HSN cell bodies are located, robustly evoked egg-laying behavior (Fig. 5A,B). By contrast, animals illuminated with a pattern of blue light that excluded the midbody laid eggs at a low frequency that was indistinguishable from the response of animals grown in the absence of all-trans retinal, an essential cofactor for ChR2.

We next measured the effects of ChR2-mediated stimulation of HSNs of unrestrained wild-type animals. We exposed transgenic adult hermaphrodites to varying intensities of blue light. Blue light robustly evoked egg laying by transgenic animals, which executed an average of four bouts of egg laying in a $30 \mathrm{~s}$ period of exposure to the highest light intensities used (Fig. 6A). The behavioral response of transgenic animals saturated at high light intensities, and half-maximal responses were evoked by $\sim 70$ $\mathrm{W} / \mathrm{m}^{2}$ of blue light. We also measured latency to first behavioral response as a function of light intensity. At the highest light intensities used, $50 \%$ of the stimulated animals showed a behavioral response within $4 \mathrm{~s}$ (Fig. 6B). As light intensities were 
A

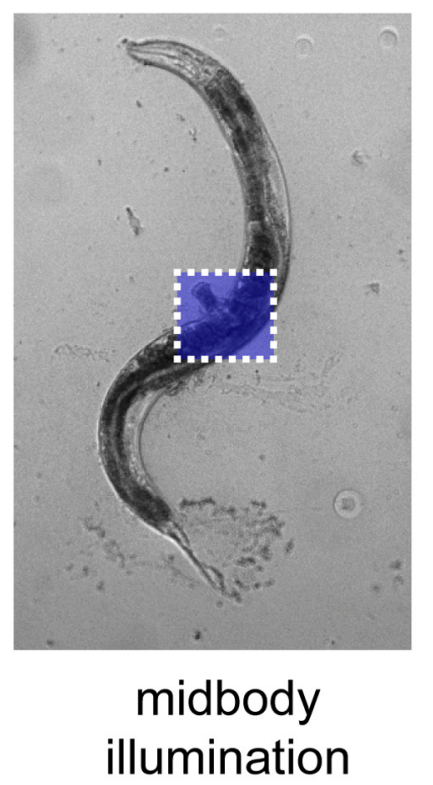

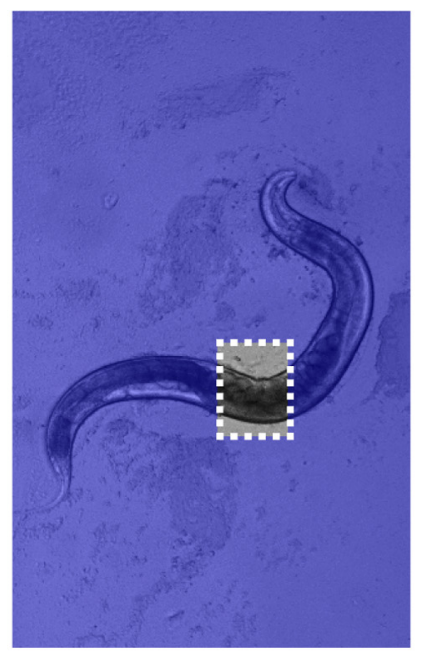

midbody-excluded illumination
B

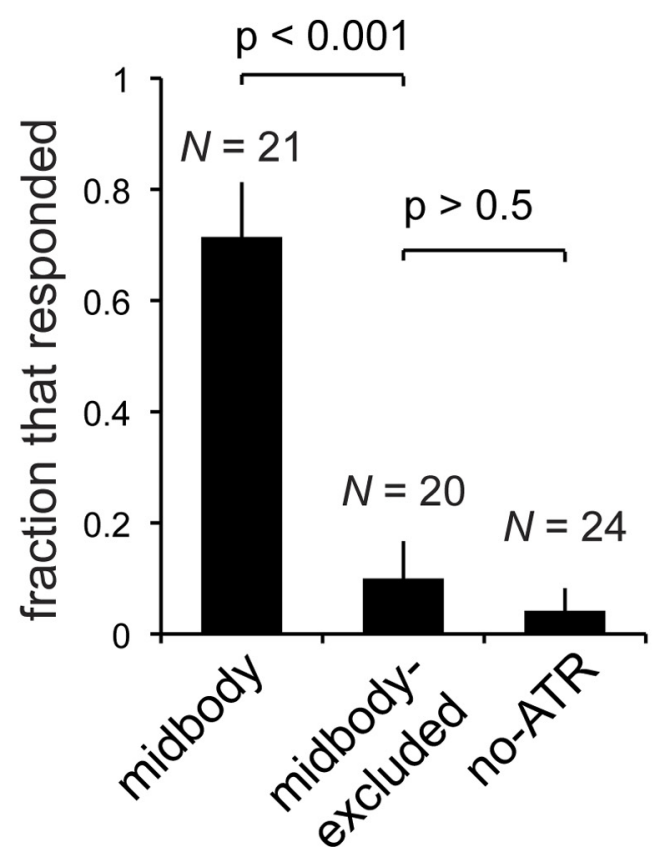

Figure 5. Photoactivation of the HSN neurons using a ChannelRhodopsin-2 transgene. A, Structured illumination of animals carrying a Prom egl-6: :ChR2 transgene. Shown are the two patterns of illumination used to stimulate transgenic animals. In the midbody, only the HSNs express the Prom ${ }_{\text {egl- } 6: . c h R 2}$ transgene. $\boldsymbol{B}$, Illumination of the midbody, but not other regions, of

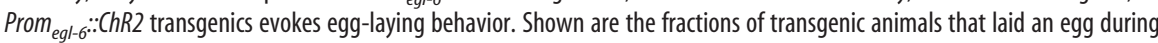
exposure to the different patterns of photostimulation \pm standard error of the proportion. Transgenic animals grown without the ATR cofactor were assayed to control for nonspecific effects of blue-light stimulation. Values of $p$ were calculated using Fisher's exact test.

reduced, the times to first response increased nonlinearly (Fig. $6 B, C)$. Animals exposed to blue light with irradiance of 29 $\mathrm{W} / \mathrm{m}^{2}$, which is $\sim 30-50$ times lower than that commonly used to stimulate C. elegans neurons (Guo et al., 2009; Leifer et al., 2011; Lindsay et al., 2011), still laid eggs within the $60 \mathrm{~s}$ observation period (Fig. $6 B, C$ ). Because the latency to first behavioral response was highly sensitive to changes in the intensity of light stimuli, we reasoned that this metric would also be highly sensitive to changes in HSN physiology and in subsequent experiments measured latencies to first behavioral response to a 29 (Fig. 7A,B).
$\mathrm{W} / \mathrm{m}^{2}$ light stimulus. Importantly, under these conditions the egg-laying behavior evoked by whole-body illumination of unrestrained transgenic animals required HSN neurons: transgenic egl-1(gf) mutants, which lack HSNs, failed to demonstrate light-evoked egg laying (Fig. 6D).

Having established a method for exciting the HSN neurons in freely behaving animals, we next tested whether $G_{o}$ signaling controls the sensitivity of the HSNs to ChR2-mediated stimulation. egl-10 encodes an RGS family GTPase-activating protein (GAP) that accelerates hydrolysis of GTP by $\mathrm{G}_{\mathrm{o}} \alpha$ and thereby antagonizes $\mathrm{G}_{\mathrm{o}}$ signaling (Koelle and Horvitz, 1996). egl-10 mutants carrying a Prom $_{\text {egl- } 6}:$ ChR2 transgene did not lay eggs in response to a photostimulus that reliably evoked egglaying behavior when applied to wild-type transgenic animals (Fig. 6E), indicating that globally increasing $G_{o}$ signaling reduced the excitability of the HSN neurons. We next measured the effect of activating $G_{o}$ signaling downstream of the EGL-6 GPCR by testing the behavioral responses of transgenic egl-6(gf) mutants to photostimulation. Like egl-10 mutants, transgenic egl-6(gf) mutants had reduced behavioral responses to photostimulation of HSN neurons (Fig. 6F). Deletion of irk-1 significantly restored the response of egl-6(gf) mutants to excitatory input (Fig. $6 F)$. irk-1 mutants themselves showed a small but significant decrease in latency to behavioral response (Fig. 6G).

\section{$\mathrm{G}_{\mathrm{o}}$ signaling that couples the EGL-6 neuropeptide receptor to IRK-1 channels is independent of other GPCR-coupled $\mathrm{G}_{\mathrm{o}}$ signaling}

The EGL-6 GPCR is one of several $\mathrm{G}_{\mathrm{o}}$ dependent receptors expressed by the HSN neurons. We asked whether IRK-1 channels are generally required for inhibition of HSN neurons by $\mathrm{G}_{\mathrm{o}}$ signaling, or whether IRK-1 channels are specifically required for signaling downstream of EGL-6 to inhibit HSNs. To address this question, we first tested whether deletion of irk-1 could efficiently suppress the egglaying defects of egl-10 mutants, which have upregulated $\mathrm{G}_{\mathrm{o}}$ signaling (Koelle and Horvitz, 1996). Surprisingly, irk-1 only weakly suppressed the egg-laying defect of egl-10(lf) mutants even though egl-10(lf) mutants were less defective in egg laying than were egl- $6(g f)$ mutants

We next tested whether IRK-1 channels are required for a different $G_{o}$ signaling pathway that inhibits the HSNs: signaling downstream of the orphan $\mathrm{G}_{\mathrm{o}}$-coupled receptor EGL-47 (Moresco and Koelle, 2004; Tanis et al., 2009). We tested whether the egl-47(gf) phenotype requires IRK-1 channels. Although EGL-47 strictly requires $G_{o}$ to inhibit HSNs (Tanis et al., 2009), loss of 
IRK-1 channels did not suppress the egglaying defects of egl-47(gf) mutants (Fig. 7C). These data suggest that, in the HSNs, there exists both $G_{o}$ signaling that strongly requires IRK-1 channels (downstream of EGL-6) and $\mathrm{G}_{\mathrm{o}}$ signaling that is independent of IRK-1 channels (downstream of EGL-47).

\section{Discussion}

An ionic mechanism for the modulation of HSN excitability by the neuropeptide receptor EGL-6

Our data indicate that $\mathrm{G}_{\mathrm{o}}$ signaling downstream of the neuropeptide receptor EGL-6 inhibits serotonergic neurons of the $C$. elegans egg-laying system via a mechanism that requires IRK-1 potassium channels. Although deletion of irk-1 only slightly changes the function of the egg-laying circuit, the same mutation strongly suppressed inhibitory effects of EGL-6 signaling both on egg-laying behavior and in assays that measure responses of the egg-laying system to direct stimulation of HSNs. This is consistent with a model in which IRK-1 channels have low constitutive activity that is increased by activation of EGL- 6 . That IRK-1 channels have constitutive activity was clearly demonstrated by the appearance of macroscopic potassium currents in $X$. laevis oocytes expressing IRK-1 in the absence of EGL- 6 or its associated G-proteins. Related vertebrate channels of the Kcnj family demonstrate constitutive activity both in vivo and in heterologous expression systems.

Regulation of ion channels is an established mechanism for the modulation of neuronal activity by GPCRs. Opening IRK-1 channels might decrease the excitability of the HSNs in two ways. First, IRK-1 channels might hyperpolarize the HSNs as they did Xenopus oocytes. Second, opening IRK-1 channels might decrease the input resistance of the HSNs, making the membrane potential less sensitive to depolarizing synaptic currents. C. elegans neurons have extremely high input resistances (Goodman et al., 1998) and are readily depolarized or hyperpolarized by synaptic currents. Indeed, we observed that ChR2-mediated stimulation of the HSN neurons could effectively evoke egg-laying behavior even when low light intensities were used, perhaps reflecting how sensitive HSNs are to such depolarizing currents. Opening IRK-1 channels could therefore both bring the resting potential of the HSNs away from a threshold required for activating voltage-sensitive membrane conductances and decrease the ability of excitatory inputs to depolarize the HSNs.

We also observed that behavioral responses to HSN photostimulation rapidly saturated, indicating that the egg-laying system does not respond in a graded manner to HSN stimulation. This nonlinearity could arise in the HSNs, which might express
$\mathrm{B}$
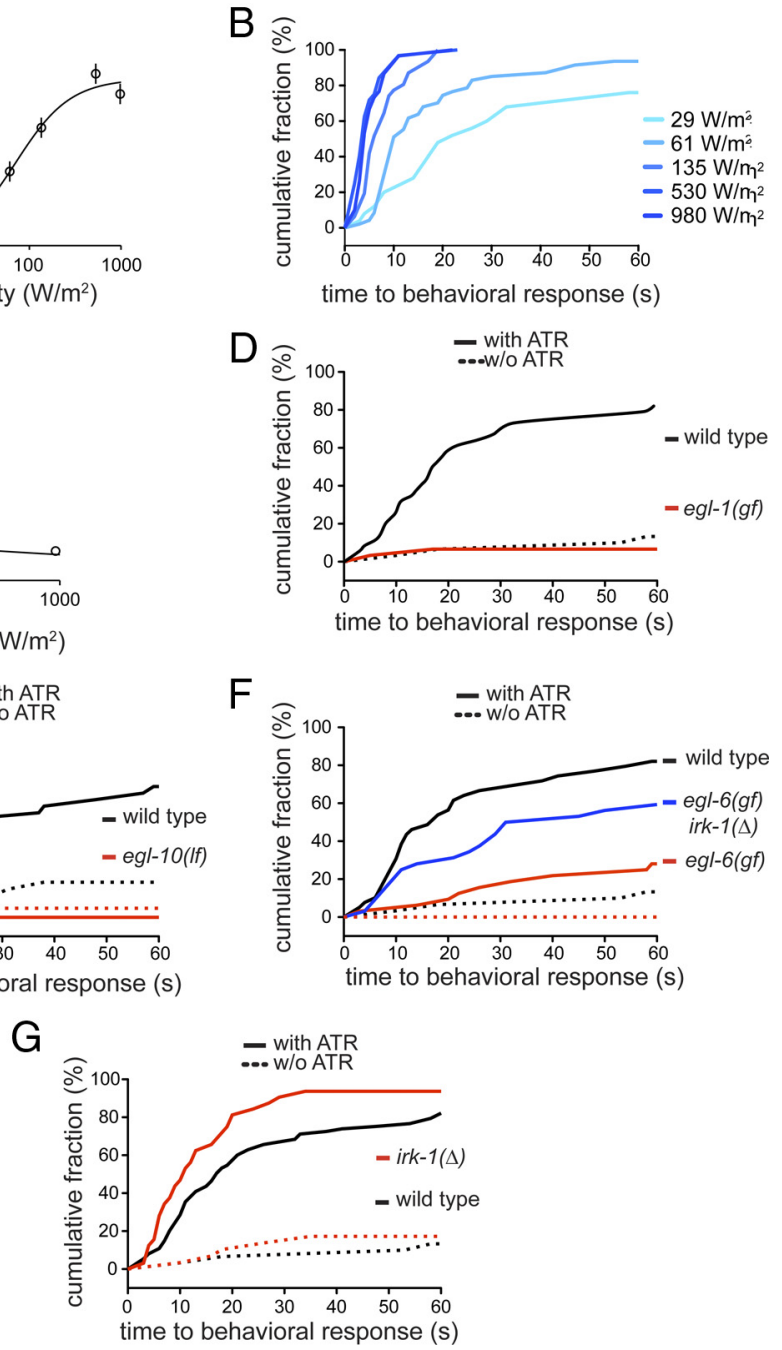

Figure 6. The regulation of HSN excitability by EGL-6 signaling is IRK-1 dependent. A, Behavioral responses of transgenic animals expressing ChR2 in the HSNs to photostimulation. Shown is the number of egg-laying events evoked by $30 \mathrm{~s}$ blue-light simuli of varying intensities (mean $\pm S E M ; N \geq 10$ animals for each point). $\boldsymbol{B}$, Latencies of behavioral responses of transgenic

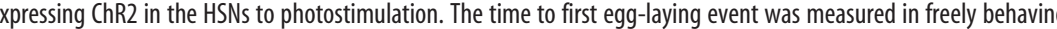
ild-type animals carrying a Prom ${ }_{\text {egl- } 6}:$ ChR2 transgene. In this panel and $\mathbf{C}-\boldsymbol{F}$, the cumulative fraction of animals that responded the photostimulus over time is plotted. $N \geq 20$ for each condition. $C$, The data in $A$ are replotted to show the times by which $50 \%$ ing of the RGS GAP protein EGL-10 were refractory to ChR2-mediated excitation. $N \geq 15$ for each condition. $\boldsymbol{F}$, The HSNs of egl-6(gf) mutants were defective in ChR2-mediated excitation in an IRK-1-dependent manner. $N \geq 15$ for each condition. G, irk-1 deletion slightly increased the sensitivity of HSNs to ChR2-mediated excitation. $N \geq 20$ for each condition.

ion channels capable of generating plateau potentials such as those observed in C. elegans sensory neurons and interneurons (Goodman et al., 1998; Mellem et al., 2008; Ramot et al., 2008). Plateau potentials allow neurons to stably maintain more than one transmembrane potential, which can correspond to discrete functional states (i.e., "on" and "off"). If HSN neurons express plateau potentials, inhibitory neuropeptides that activate EGL-6, and subsequently activate IRK-1 channels, might regulate such state transitions to favor hyperpolarized states. Alternately, the nonlinearity of behavioral responses to increasing HSN stimulation might arise in the vulval muscle, which might integrate synaptic input from the HSNs until a threshold for contraction is reached. In either model, small changes in HSN membrane conductances caused by activation of IRK-1 channels could cause large changes in the function of the egg-laying circuit. It is inter- 
A
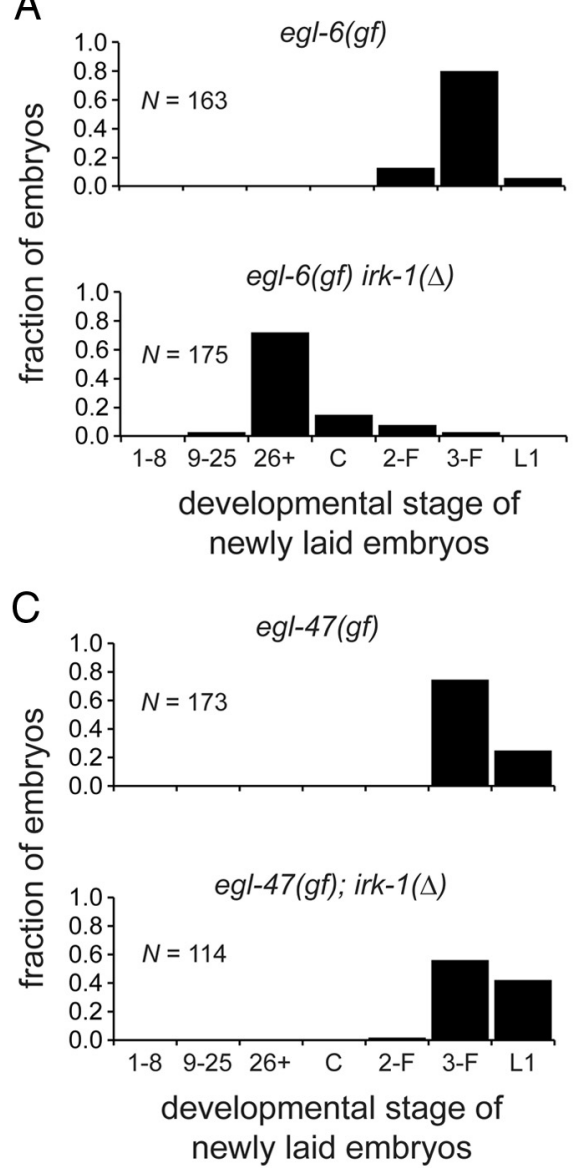

$\mathrm{B}$

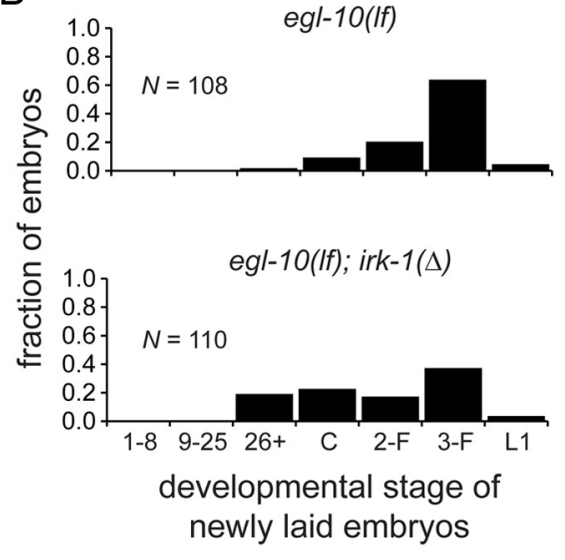

D

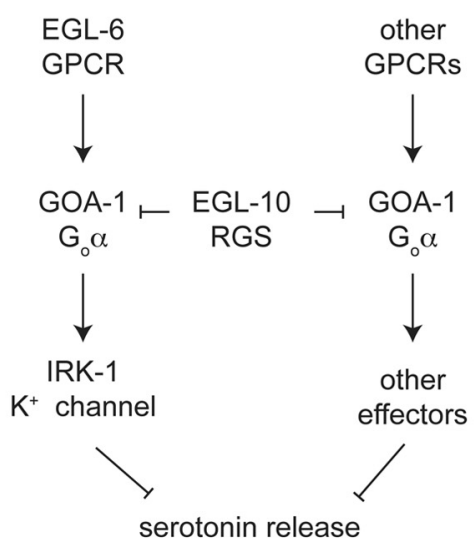

Figure 7. $G_{0}$ signaling downstream of the neuropeptide receptor EGL-6 is especially sensitive to irk-1 mutation. $A$, The egglaying defect of egl-6(gf) mutants as measured by the abnormally late developmental stages of newly laid eggs was strongly suppressed by irk-1 deletion. $B$, The egg-laying defect of egl-10 mutants, which have increased $G_{0}$ signaling caused by loss of an RGS protein that inhibits $G_{0} \alpha$, was only partly suppressed by irk-1 deletion. $C$, The egg-laying defect of animals carrying a gain-of-function mutation in $E G L-47$, another $G_{0}$-coupled receptor that inhibits HSNs, was not suppressed by irk-1 deletion. $D, A$ model for the function of IRK-1 channels in the regulation of $\mathrm{HSN}_{\mathrm{S}}$ by $\mathrm{G}_{0}$ signaling.

esting to speculate that regulation of IRK-1 channels by neuropeptide signaling is integrated with regulation of other ion channels to finely tune the activity of the egg-laying system in response to changes in the environment or internal state.

\section{IRK-1 channels might be homologous to vertebrate G-protein-gated channels}

IRK-1 is an ion channel subunit similar to vertebrate Kcnj3, Kcnj5, Kcnj6, and Kcnj9, which are subunits of G-proteinregulated potassium channels. Does IRK-1 also form channels that are directly regulated by G-protein subunits? That eliminating irk-1 function did not enhance the effect of a goa-1 mutation on EGL-6 signaling is consistent with a model in which IRK-1 channels are downstream of $G_{o}$, although we cannot preclude the possibility that IRK-1 channels act in parallel to $G_{0}$. The primary sequence of IRK-1 suggests that IRK-1 channels might be directly regulated by $\mathrm{G}_{\mathrm{o}}$ subunits. Sequences forming a pair of $\beta$ strands called the $\beta \mathrm{L}-\beta \mathrm{M}$ loop are both required for the activation of vertebrate Kcnj channels by G-protein $\beta \gamma$ subunits and form part of the interaction surface between KCNJ channels and G $\beta \gamma$. These sequences are partly conserved between vertebrate G-protein-gated Kcnj channels and IRK-1 (Fig. 3B), suggesting that like Kcnj channels IRK-1 might bind G $\beta \gamma$ subunits and un- dergo the specific conformational changes that accompany $\mathrm{G} \beta \gamma$ binding (Whorton and MacKinnon, 2011).

G-proteins also regulate ion channels through second messenger signaling. For example, muscarinic acetylcholine receptors in vertebrate neurons alter cell excitability through the modulation of voltage-sensitive potassium channels in the Kcnq family, which are gated by the phospholipid phosphatidylinositol $(4,5)$ bisphosphate $\left(\mathrm{PIP}_{2}\right)$, the levels of which are controlled by G-protein signaling (Suh and Hille, 2008). Like Kcnq channels, Kcnj channels are regulated by $\mathrm{PIP}_{2}$ (Huang et al., 1998). A recent crystal structure of $\mathrm{PIP}_{2}-$ bound Kcnj6 revealed that binding of $\mathrm{PIP}_{2}$ induces a conformational change in the channel that is distinct from and synergizes with the proposed effect of $G \beta \gamma$ binding, and also identified residues that mediate interactions with $\mathrm{PIP}_{2}$ (Whorton and MacKinnon, 2011). In Kcnj6 channels, $\mathrm{PIP}_{2}$ is coordinated by lysine residues, which are conserved between Kcnj channels and IRK-1. Thus, the primary sequence of IRK-1 channel subunits suggests two mechanisms that might couple these channels to G-protein signaling pathways: direct interaction with G-protein subunits, and regulation by $\mathrm{PIP}_{2}$.

\section{$\mathrm{G}_{\mathrm{o}}$ signaling in the HSN neurons might} be functionally compartmentalized Our results show that not all $\mathrm{G}_{\mathrm{o}}$ dependent inhibitory pathways in the HSNs strongly depend on IRK-1 channels. The egg-laying defect of egl-10 mutants, which are mutant for a GAP that acts on $\mathrm{G}_{\mathrm{o}} \alpha$ (Koelle and Horvitz, 1996), was only weakly suppressed by irk-1 deletion, indicating that a significant amount of $G_{o}$ signaling in the egg-laying system does not require IRK-1 channels. Inhibition of HSNs by the orphan receptor EGL-47 did not require IRK-1 channels at all. While EGL-47 is a divergent member of the GPCR family (Moresco and Koelle, 2004) and might function in a manner different from EGL-6, which is a rhodopsin-like GPCR (Ringstad and Horvitz, 2008), both receptors share a requirement for $\mathrm{G}_{\mathrm{o}}$ to inhibit HSNs, suggesting that both are $\mathrm{G}_{\mathrm{o}}$-coupled receptors (Moresco and Koelle, 2004). We cannot rule out by genetic arguments, however, that EGL-47 signaling and $\mathrm{G}_{\mathrm{o}}$ signaling function in parallel to inhibit the HSNs, thereby explaining the lack of a requirement for IRK-1 channels in EGL-47 signaling. It is also possible that some mutations studied affect components of the egg-laying system other than the HSNs, while the function of EGL-6 and IRK-1 channels is specific to the HSNs. We note, however, that EGL-10 expression is enriched in the HSNs (Koelle and Horvitz, 1996) and the HSNs have been shown to be the focus of $G_{o}$ signaling in the egg-laying system (Tanis et al., 2008). It is therefore likely that the effects of mutating $G_{o}$ signaling pathways specifically alter HSN function.

Another explanation for the ability of irk-1 mutation to suppress the effects of activating one $\mathrm{G}_{\mathrm{o}}$-dependent receptor signal- 
ing pathway but not another is that $G_{o}$ signaling in the HSN neurons is functionally compartmentalized. How could such functional compartmentalization of $G_{o}$ signaling occur? In vertebrate neurons, a given $\mathrm{G} \alpha$ subunit can associate with many combinations of $\beta$ and $\gamma$ subunits. One determinant of the functional relationship between a GPCR and its effectors is the composition of receptor-associated heterotrimeric G-proteins. C. elegans, however, expresses only one $\mathrm{G}_{\mathrm{o}} \alpha$ subunit, and the HSN neurons are only known to express one of the two $\beta$ subunits and one of the two $\gamma$ subunits encoded by the $C$. elegans genome. Therefore, the specific association of IRK-1 channels with EGL-6 is unlikely to be mediated by diversity in $G_{0}$ molecules in the HSNs.

In vertebrate neurons, GPCRs couple to distinct effectors depending on where in the cell they are located. For example, metabotropic $\mathrm{G}_{\mathrm{i} / \mathrm{o}}$-coupled GABA receptors couple to $\mathrm{Kcnj}$ family potassium channels postsynaptically to regulate action potential generation (Lüscher et al., 1997), but act on different effectors presynaptically to regulate release probability. We found no evidence that the cell surface expression of either the neuropeptide receptor EGL-6 or IRK-1 channels was restricted to a particular part of the HSN: we observed both proteins on the cell soma and the neurite, including regions of the neurite that are enriched for presynapses. It is possible that IRK-1 channels associate with EGL-6 in microdomains that are distributed over the cell surface. Vertebrate Kcnj channels associate with G-protein-coupled $\mathrm{GABA}_{\mathrm{B}}$ receptors (Fowler et al., 2007), suggesting the existence of a preformed signaling complex. In some cells, GPCRs and KCNJ channels associate with a GAP that acts on $\mathrm{G}_{\mathrm{i} / \mathrm{o}}$ (Labouèbe et al., 2007), indicating that the organization of GPCR signaling complexes differs between cell types and that such complexes can include both positive and negative regulators of Kcnj channels. In the C. elegans HSN neurons, the neuropeptide receptor EGL-6 might function in a signaling complex similar to that described for the vertebrate $G_{A B A}$ receptor. Such a complex would account for the specific functional association that we observed between EGL-6 and IRK-1 channels. Also, discrete GPCR signaling complexes that match a receptor to an effector would allow $C$. elegans neurons to generate diverse responses to activation of different GPCRs in the absence of molecular diversity of G-protein subunits. Mechanisms that mediate the specific functional association of EGL-6 with IRK-1 channels might exist in vertebrate neurons and contribute to the diversity and complexity of their responses to GPCR activation.

\section{References}

Bany IA, Dong MQ, Koelle MR (2003) Genetic and cellular basis for acetylcholine inhibition of Caenorhabditis elegans egg-laying behavior. J Neurosci 23:8060-8069.

Bargmann CI (1998) Neurobiology of the Caenorhabditis elegans genome. Science 282:2028-2033.

Brenner S (1974) The genetics of Caenorhabditis elegans. Genetics 77:71-94.

Carnell L, Illi J, Hong SW, McIntire SL (2005) The G-protein-coupled serotonin receptor SER-1 regulates egg laying and male mating behaviors in Caenorhabditis elegans. J Neurosci 25:10671-10681.

Drenkard E, Richter BG, Rozen S, Stutius LM, Angell NA, Mindrinos M, Cho RJ, Oefner PJ, Davis RW, Ausubel FM (2000) A simple procedure for the analysis of single nucleotide polymorphisms facilitates map-based cloning in Arabidopsis. Plant Physiol 124:1483-1492.

Fang-Yen C, Gabel CV, Samuel AD, Bargmann CI, Avery L (2012) Laser microsurgery in Caenorhabditis elegans. Methods Cell Biol 107:177-206.

Fowler CE, Aryal P, Suen KF, Slesinger PA (2007) Evidence for association of $\mathrm{GABA}_{\mathrm{B}}$ receptors with Kir3 channels and regulators of $\mathrm{G}$ protein signalling (RGS4) proteins. J Physiol 580:51-65.

Goodman MB, Hall DH, Avery L, Lockery SR (1998) Active currents regulate sensitivity and dynamic range in C. elegans neurons. Neuron 20:763-772.

Guo ZV, Hart AC, Ramanathan S (2009) Optical interrogation of neural circuits in Caenorhabditis elegans. Nat Methods 6:891-896.

Hallem EA, Spencer WC, McWhirter RD, Zeller G, Henz SR, Rätsch G, Miller DM, Horvitz HR, Sternberg PW, Ringstad N (2011) Receptor-type guanylate cyclase is required for carbon dioxide sensation by Caenorhabditis elegans. Proc Natl Acad Sci U S A 108:254-259.

Herlitze S, Garcia DE, Mackie K, Hille B, Scheuer T, Catterall WA (1996) Modulation of $\mathrm{Ca}^{2+}$ channels by G-protein beta gamma subunits. Nature 380:258-262.

Hobson RJ, Hapiak VM, Xiao H, Buehrer KL, Komuniecki PR, Komuniecki RW (2006) SER-7, a Caenorhabditis elegans 5- $\mathrm{HT}_{7}$-like receptor, is essential for the 5-HT stimulation of pharyngeal pumping and egg laying. Genetics 172:159-169.

Huang CL, Feng S, Hilgemann DW (1998) Direct activation of inward rectifier potassium channels by PIP2 and its stabilization by Gbetagamma. Nature 391:803-806.

Iversen LL, Iversen SD, Bloom FE, Roth RH (2009) Introduction to neuropsychopharmacology, Ed 8. Oxford: Oxford UP.

Jansen G, Hazendonk E, Thijssen KL, Plasterk RH (1997) Reverse genetics by chemical mutagenesis in Caenorhabditis elegans. Nat Genet 17: $119-121$.

Kim K, Li C (2004) Expression and regulation of an FMRFamide-related neuropeptide gene family in Caenorhabditis elegans. J Comp Neurol 475: $540-550$.

Koelle MR, Horvitz HR (1996) EGL-10 regulates G protein signaling in the C. elegans nervous system and shares a conserved domain with many mammalian proteins. Cell 84:115-125.

Kubo Y, Reuveny E, Slesinger PA, Jan YN, Jan LY (1993) Primary structure and functional expression of a rat G-protein-coupled muscarinic potassium channel. Nature 364:802-806.

Labouèbe G, Lomazzi M, Cruz HG, Creton C, Luján R, Li M, Yanagawa Y, Obata K, Watanabe M, Wickman K, Boyer SB, Slesinger PA, Lüscher C (2007) RGS2 modulates coupling between $\mathrm{GABA}_{\mathrm{B}}$ receptors and GIRK channels in dopamine neurons of the ventral tegmental area. Nat Neurosci 10:1559-1568.

Lee YS, Park YS, Nam S, Suh SJ, Lee J, Kaang BK, Cho NJ (2000) Characterization of GAR-2, a novel G protein-linked acetylcholine receptor from Caenorhabditis elegans. J Neurochem 75:1800-1809.

Lefkowitz RJ, Shenoy SK (2005) Transduction of receptor signals by betaarrestins. Science 308:512-517.

Leifer AM, Fang-Yen C, Gershow M, Alkema MJ, Samuel AD (2011) Optogenetic manipulation of neural activity in freely moving Caenorhabditis elegans. Nat Methods 8:147-152.

Liman ER, Tytgat J, Hess P (1992) Subunit stoichiometry of a mammalian $\mathrm{K}^{+}$channel determined by construction of multimeric cDNAs. Neuron 9:861-871.

Lindsay TH, Thiele TR, Lockery SR (2011) Optogenetic analysis of synaptic transmission in the central nervous system of the nematode Caenorhabditis elegans. Nat Commun 2:306.

Lu B, Su Y, Das S, Wang H, Wang Y, Liu J, Ren D (2009) Peptide neurotransmitters activate a cation channel complex of NALCN and UNC80. Nature 457:741-744.

Luján R, Maylie J, Adelman JP (2009) New sites of action for GIRK and SK channels. Nat Rev Neurosci 10:475-480.

Lüscher C, Jan LY, Stoffel M, Malenka RC, Nicoll RA (1997) G proteincoupled inwardly rectifying $\mathrm{K}^{+}$channels (GIRKs) mediate postsynaptic but not presynaptic transmitter actions in hippocampal neurons. Neuron 19:687-695.

Mellem JE, Brockie PJ, Madsen DM, Maricq AV (2008) Action potentials contribute to neuronal signaling in C. elegans. Nat Neurosci 11:865-867.

Mello C, Fire A (1995) DNA transformation. Methods Cell Biol 48:451-482.

Mello CC, Kramer JM, Stinchcomb D, Ambros V (1991) Efficient gene transfer in C. elegans: extrachromosomal maintenance and integration of transforming sequences. EMBO J 10:3959-3970.

Moresco JJ, Koelle MR (2004) Activation of EGL-47, a G $\alpha_{\mathrm{o}}$-coupled receptor, inhibits function of hermaphrodite-specific motor neurons to regulate Caenorhabditis elegans egg-laying behavior. J Neurosci 24:8522-8530.

Nagel G, Brauner M, Liewald JF, Adeishvili N, Bamberg E, Gottschalk A (2005) Light activation of channelrhodopsin-2 in excitable cells of Caenorhabditis elegans triggers rapid behavioral responses. Curr Biol 15:2279-2284. 
Nurrish S, Ségalat L, Kaplan JM (1999) Serotonin inhibition of synaptic transmission: Galpha ${ }_{0}$ decreases the abundance of UNC-13 at release sites. Neuron 24:231-242.

Ramot D, MacInnis BL, Goodman MB (2008) Bidirectional temperaturesensing by a single thermosensory neuron in C. elegans. Nat Neurosci 11:908-915.

Reuveny E, Slesinger PA, Inglese J, Morales JM, Iñiguez-Lluhi JA, Lefkowitz RJ, Bourne HR, Jan YN, Jan LY (1994) Activation of the cloned muscarinic potassium channel by $G$ protein beta gamma subunits. Nature 370:143-146.

Ringstad N, Horvitz HR (2008) FMRFamide neuropeptides and acetylcholine synergistically inhibit egg-laying by C. elegans. Nat Neurosci 11:1168-1176.

Sbalzarini IF, Koumoutsakos P (2005) Feature point tracking and trajectory analysis for video imaging in cell biology. J Struct Biol 151:182-195.

Ségalat L, Elkes DA, Kaplan JM (1995) Modulation of serotonin-controlled behaviors by Go in Caenorhabditis elegans. Science 267:1648-1651.

Sieburth D, Madison JM, Kaplan JM (2007) PKC-1 regulates secretion of neuropeptides. Nat Neurosci 10:49-57.

Suh BC, Hille B (2008) PIP2 is a necessary cofactor for ion channel function: how and why? Annu Rev Biophys 37:175-195.
Takigawa T, Alzheimer C (2002) Phasic and tonic attenuation of EPSPs by inward rectifier $\mathrm{K}^{+}$channels in rat hippocampal pyramidal cells. J Physiol 539:67-75.

Tanis JE, Moresco JJ, Lindquist RA, Koelle MR (2008) Regulation of serotonin biosynthesis by the $\mathrm{G}$ proteins Galphao and Galphaq controls serotonin signaling in Caenorhabditis elegans. Genetics 178:157-169.

Tanis JE, Bellemer A, Moresco JJ, Forbush B, Koelle MR (2009) The potassium chloride cotransporter KCC-2 coordinates development of inhibitory neurotransmission and synapse structure in Caenorhabditis elegans. J Neurosci 29:9943-9954.

White JG, Southgate E, Thomson JN, Brenner S (1986) The Structure of the nervous system of the nematode Caenorhabditis elegans. Philos Trans R Soc Lond B Biol Sci 314:1-340.

Whorton MR, MacKinnon R (2011) Crystal structure of the mammalian GIRK2 $\mathrm{K}^{+}$channel and gating regulation by G proteins, PIP2, and sodium. Cell 147:199-208.

Zimmer M, Gray JM, Pokala N, Chang AJ, Karow DS, Marletta MA, Hudson ML, Morton DB, Chronis N, Bargmann CI (2009) Neurons detect increases and decreases in oxygen levels using distinct guanylate cyclases. Neuron 61:865-879. 